http:/ / dx.doi.org/10.21707/gs.v11.n02a19

\title{
VALORAÇÃo CONTIGENTE DO RIO JAGUARIBE
}

\section{Marcella Braga Tavares ${ }^{1}$, Márcia Batista da Fonseca ${ }^{2 *}$}

\author{
${ }^{1}$ Docente do Curso de Economia e Gestão - Instituto Federal da Paraíba,JP \\ ${ }^{2}$ Docente do Departamento de Economia, Universidade Fedearl da Paraiba \\ *Autorpara correspondência:mbf.marcia@gmail.com
}

Recebido em 19 de fevereiro de 2016. Aceito em 04 de março de 2017. Publicado em 29 de julho de 2017.

Resumo - O Rio Jaguaribe situado na cidade de João Pessoa, estado da Paraíba, é o principal rio em termos de drenagem urbana, cortando a cidade João Pessoa no sentido oeste/leste. Dada esta situação, o rio vem sofrendo diversos impactos ambientais advindos da ação humana. Pode-se destacar o aparecimento de comunidades ribeirinhas, desmatamento, queimadas, deposições de resíduos sólidos e líquidos, o que tem causado um processo de envenenamento de suas águas. Este estudo é um exercício empírico, que investiga por meio da valoração contingente, a Disposição a Pagar (DAP) dos agentes econômicos pela conservação e manutenção do Rio Jaguaribe (PB). Utilizou-se uma amostra aleatória de 50 indivíduos para a aplicação de uma entrevista semiestruturada. O modelo econométrico logit foi utilizado para estimar a DAP dado que é um modelo de seleção qualitativa. Os resultados apontam que o índice de aceitação da DAP foi relativamente alto, 47,5\% dos respondentes aceitaram o valor apresentado. A partir dos resultados referentes à DAP aberta, observa-se um menos índice de rejeição. O valor médio da DAP aberta foi de R $\$ 2,50$. Do total de entrevistados, cerca de 76\% dos entrevistados declararam um não valor nulo. Ou seja, mais da metade da amostra está disposta a pagar algum valor não nulo para a efetivação e manutenção do Rio Jaguaribe.

Palavras-Chave: Valoração Contigente; DAP; Logit.

\section{Contingent valuationof the Jaguaribe River}

\begin{abstract}
Aвstract - The Jaguaribe River, located in the city of João Pessoa, Paraíba State, Brazil, is the main river in terms of urban drainage, crossing João Pessoa in west-east direction. Due to this fact, this river has hadseveral environmental impacts caused by human activity. It can be highlighted the settlement of river side communities, deforestation, forest fire, and disposal of solid and liquid waste in the river, which has caused the poisoning of its water. This study is an empirical exercise which investigates, through contingent valuation, the willingness to pay (WTP) of economic agents for the conservation and maintenance of the Jaguaribe River. A random sample of 50 individuals was used in a semi-structured interview. The logit econometric model was used to estimate the WTP since it is a qualitative selection model. The results showed a WTP acceptance rate relatively high; 47.5\% of the respondents agreed on the presented value. From the results relating to the open WTP, it is observed a lower rejection rate. The average value of the open WTP was $\mathrm{R} \$ 2.50$. About $76 \%$ of the total respondents reported a non-zero value. Thus, over half of the sample is willing to pay some non zero value for the effectivation and maintenance of the Jaguaribe River.
\end{abstract}

Keywords: CONTINGENT VALUATION; WTP, LOGIT.

\section{VALORACIÓN CONTINGENTE DEL RÍo JAGUARIBE}

Resumen - El Río Jaguaribe, ubicado en la ciudad de João Pessoa, en elestado de Paraíba, Brasil, es el río principal en términos de drenaje urbano, cruzando la dicha ciudad de oeste a este. Ante esta situación, el río ha sufrido varios impactos 
ambientales debido a las actividades humanas. Entre ellas, se destacan el establecimiento de comunidades ribereñas, la deforestación, las quemas, y la deposición de desechos sólidos y líquidos en el río, lo que ha provocado el envenenamiento de sus aguas. Este estudio es un ejercicio empírico, que investiga a través de la valoración contingente, la disposición a pagar (DAP) de los agentes económicos por la conservación y mantenimiento del Río Jaguaribe. Se utilizó una muestra aleatoria de 50 personas para la aplicación de una entrevista semiestructurada. El modelo econométrico logit se utilizó para estimar la DAP ya que es un modelo de selección cualitativa. Los resultados muestran que la tasa de aceptación de la DAP fue relativamente alta; el 47,5\% de los encuestados aceptó el valor obtenido. De los resultados de la DAP abierta, se observa que la tasa de rechazo fue menor. El valor promedio de la DAP abierta fue de R $\$ 2,50$. Alrededor del 76\% de los encuestados declaró un valor no nulo. Por lo tanto, más de la mitad de la muestra está dispuesta a pagar un valor no nulo para la efectuación y el mantenimiento del Río Jaguaribe.

Palabras clave: V aloración Contingente; DAP; Logit.

\section{INTRODUÇÃO}

A utilização intensiva dos recursos naturais renováveis e não-renováveis trouxe à sociedade a preocupação com a inter-relação existente entre crescimento e desenvolvimento econômico com o meio ambiente. Assim, surgiu a necessidade de conciliar variáveis econômicas com a questão ambiental, com o intuito de possibilitarum relacionamento mais harmônico entre as necessidades humanas infinitas e as disponibilidades ambientais limitadas.

Segundo Pearce (1993), os recursos naturais e ambientais geram diversos bens e serviços que são refletidos, sobretudo, no bem-estar geral dos indivíduos. Alguns desses benefícios podem ser valorados com certa facilidade por estarem relacionados de alguma forma com o sistema de mercado (produção de alimentos, minérios, por exemplo). Porém, outros bens e serviços gerados pelo meio ambiente, como recreação/turismo, por não possuírem preços de mercado, são extremamente difíceis deserem mensurados monetariamente através da teoria econômica "tradicional".

A dificuldade encontrada em valorar monetariamente alguns benefícios gerados pelomeio ambiente, advém do fato dos recursos naturais serem considerados bens públicos eapresentarem algumas característicaspeculiares como as de não-exclusão e não-rivalidade. Tais características, em geral, fazem com que o mercado deixe de operar de forma eficiente e comece a operar com falhas. Nos casos em que é possível estabelecer o preço de mercado para as amenidades ambientais, este geralmente é menor do que o preço considerado eficiente, fazendo com que haja uma sobre-exploração do recurso natural, e consequentemente, sua exaustão.

Nesse contexto, a valoração de ativos ambientais procuraapresentar um preço para o recurso ambiental, possibilitando a criação de políticas objetivandoharmonizar a manutenção e conservação do meio ambiente com as necessidades humanas e econômicas.

Segundo Motta (1998) "determinar o valor econômico de um recurso ambiental é estimar o valor monetário deste com relação aos outros bens e serviços disponiveis na economia". Ainda segundo este autor, a valoração "consiste em determinar quanto melhor ou pior estará o bem-estar das pessoas devido a mudanças na quantidade de bens e serviços ambientais, seja na apropriação do uso ou não". Ainda, de acordo com Nogueira, Medeiros e Arruda (2000), a valoração ambiental é utilizada "para estimar os valores que as pessoas atribuem aos recursos ambientais, com base em suas preferências individuais".

Ainda segundo Motta (1998) categoricamente pode-se destacar duas formas de avaliar os ativos ambientais, 
via Técnicas Diretas de Valoração (Função demanda) - buscam obter a preferência revelada dos consumidores dos serviços ambientais para estimar a sua disposição a pagar (DAP) pela conservação de tais serviços - 2) Técnicas indiretas de valoração (Função oferta) - recuperam o valor dos bens e serviços ambientais através das alterações nos preços de produtos de mercado resultantes das mudanças ambientais. Este estudo opta por uma técnica direta de valoração ambiental que é o Método de Valoração Contingente (MVC).

O objeto de pesquisa deste estudo é o Rio Jaguaribeque nasce ao sul de João Pessoa - Paraíba,no conjunto Esplanada, em uma lagoa, hoje aterrada. O curso d'água possui umaextensão aproximada de $21 \mathrm{~km}$, até a sua desembocadura, no Oceano Atlântico, entre a praia de Ponta de Campina e o Bessa, no Maceió do Jardim América, hoje o bairro de Intermares no litoral do estado. Seus principais afluentes são: o rio Timbó, pela margem direita, e o Riacho dos Macacos na margem esquerda, hoje desaparecido em razão da expansão do bairro da Torre e de parte do bairro de Jaguaribe. Pequenos córregos e drenos completam o sistema de drenagem. O Rio Jaguaribe é alimentado por várias fontes e ressurgências situadas entre o seu curso superior e o lago de barragem da reserva florestal do buraquinho, hoje Jardim Botânico Benjamim Maranhão (Melo 2001 s.p.).

Segundo ICMBIO (2014) o Domínio da Mata Atlântica (DMA) na Paraíba abrange um total de 6.743 $\mathrm{Km}^{2}$ e ocupa total ou parcialmente 63 municípios, incluindo os ecossistemas de mata, restinga e manguezal. A região por onde passa o rio, inserido no Bioma Mata Atlântica, foi identificada como uma região prioritária para conservação, estando situada dentro perímetro urbano de João Pessoa e desembocando no Rio Paraíba. Por essa característica, o rio Jaguaribe sobre de alto grau de poluição. Por ser um rio urbano, várias de suas áreas já foram transformadas em esgoto a céu aberto.

O Rio Jaguaribe é um bem público, mais precisamente um ativo ambiental, a disposição a pagar pela conservação e manutenção desse ativo não indica somente um valor que reflete as preferências dos indivíduos, mais possibilita averiguar o grau de conscientização da sociedade acerca da preservação de um recurso ambiental.

Devido ao fato de ser um rio urbano, o Rio Jaguaribe está sujeito a um elevado grau de poluição ambiental, e problemas como desmatamento, assoreamento, destruição da mata ciliar, poluição da agua do rio com rejeitos de esgoto e problemas ligados a construção de infraestrutura, como pontes, rodovias e obras no seu entorno tem causado a sua degradação.

Este estudo este inserido dentro do projeto de pesquisa cadastrado no Departamento de Economia da Universidade Federal da Paraíba (UFPB), intitulado "Sistema de Pagamentos por Serviços Ambientais: Propostas para o Estuário do Rio Paraíba”, que objetiva realizar estudos de diagnósticos e Valoração ambiental na Paraíba. O grupo de estudo e pesquisa "Meio Ambiente e Políticas Públicas" da mesma universidade, tem contribuído na formulação e implementação de políticas públicas ambientais, ao propor um novo modelo de gestão ambiental, baseado na utilização de forma sustentável dos recursos ambientais.

Conforme Silva (2003), a importância da valoração ambiental reside no fato de que esta é essencial para criar um valor de referência que indique uma sinalização de mercado, possibilitando, assim, o uso "racional" dos recursos ambientais. Com isso, os agentes públicos e privados terão subsídios para avaliação econômica de tomadas de decisões políticas sobre a utilização eficiente desses ativos. Logo, a criação de um valor de referência para um bem ambiental fornece informações ao poder público, à sociedade civil organizada e às organizações não governamentais (ONGs), possibilitando um gerenciamento mais eficaz desses recursos.

Neste estudo utiliza-se o MVC para estimar benefícios e custos ambientais. Por meio deste busca-se descobrir o quanto as pessoas estão dispostas a pagar por determinado ativo ambiental, e esse então, torna-se o 
valor aproximado do quanto este ativo gera de benefícios para o indivíduo em questão. Para tanto, é proposto um mercado hipotético em que os agentes devem apresentar suas preferencias e a partir destas, a disposição a pagar é encontrada sendo uma proxy da função demanda para o ativo ambiental. Este método fora escolhido para ser usado neste estudo, devido ao fato de abranger todos os valores que um ativo ambiental pode receber, que segundo Motta (1998) são os valores de uso, de não uso e o valor de mercado.

Dada a importância do Rio Jaguaribe para a sociedade pessoense e tendo em vista que se tratade um bem público onde não há um mercado específico, a fim de se deduzir o preço de mercado do mesmo, questionase:quanto vale a manutenção e conservação do Rio Jaguaribe? Mais especificamente: quanto o agente estaria disposto a pagar para que a disponibilidade de serviços ambientais fornecidos pelo Rio Jaguaribe não diminua?

O objetivo central deste estudo de caráter quantitativo é verificar se a sociedade paraibana possui a percepção de que a manutenção e conservação do Rio Jaguaribe aumentam o seu nível de bem-estar. Especificamente pretende-se:

a) Estimar o valor econômico do Rio Jaguaribe;

b) Estimar via modelo Logite analisar a disposição a pagar (DAP) manifestada (stated willingness-to-pay) e a verdadeira disposição a pagar (true willingness-to-pay) paramanutenção e conservação do Rio Jaguaribe.

Os resultados desta pesquisa podem ser utilizados para obter um valor econômico para o bem púbico, o rio, ou para derivar valores sociais tanto para usuários quanto para não usuários do bem em questão. Assim sendo, este trabalho busca estimar, através do MVC, um valor de mercado para o Rio Jaguaribe (PB). A pesquisa justifica-se pelo fato de oferecer à sociedade paraibana um estudo que evidencia o grau de percepçãodo cidadão pessoense quanto à manutenção e conservação de um bem público, no caso, o Rio Jaguaribe.

Entendendo-se percepção no sentido de "percepção ambiental" como um processo em que as informações percebidas pelos indivíduos se constituem em elementos utilizados na formação de uma avaliação para a valoração dos bens ambientais.

Além desta introdução este estudo apresenta o referencial teórico voltado a analise microeconômica do comportamento do consumidor e a valoração de ativos ambientais, em seguida a metodologia empregada seguida de resultados e considerações finais.

\section{O Comportamento do Consumidor e Disposição a Pagar}

A teoria microeconômica do consumidor postula que os indivíduos são racionais e se comportam para atingir o maior nível possível de satisfação. Logo, se as preferências são ordenadas, elas podem ser representadas pela função de utilidade direta (FUD), da seguinte forma:

$$
\mathrm{U}=\mathrm{U}(\mathrm{X}, \mathrm{Q}, \mathrm{T})
$$

Em que:

U: é a utilidade do consumidor; X: é um vetor de quantidade dos bens de mercado; Q: vetor de bens públicos (recursos e serviços ambientais), em que as quantidades são fixadas pelo indivíduo; T: vetor de tempo utilizado em várias atividades que produzem a utilidade do indivíduo.

Considerando-se que as escolhas dos indivíduos objetivam maximizar sua utilidade, dados os preços e dada a existência de uma restrição orçamentária, sendo a renda fixa, o problema de maximização de utilidade do 
consumidor pode ser expresso da seguinte forma:

$$
\operatorname{Max} \mathrm{U}=\mathrm{U}(\mathrm{X}), \mathrm{s} . \mathrm{a} \sum P i x X i=M
$$

Em que:

$\mathrm{X}$ é um vetor de quantidades $(\mathrm{X}=\mathrm{X} 1, \mathrm{X} 2, \mathrm{X} 3 \ldots, \mathrm{Xn}) ; \mathrm{P}$, vetorde preços $(\mathrm{P}=\mathrm{P} 1, \mathrm{P} 2, \mathrm{P} 3, \ldots, \mathrm{Pn})$; $M$, renda.

A solução desse problema fornece a função de demanda ordinária (função de demanda marshaliana), dada por:

$$
\mathrm{Xi}=\mathrm{Xi}(\mathrm{P}, \mathrm{M})
$$

A equação (3) relaciona a quantidade ótima de determinado bemcom os preços e com a renda monetária constante. Ao determinar asquantidades ótimas de cada bem Xi, o consumidor estará atingindo o maior nível possível de utilidade. A partir da determinação das demandasmarshalianas é possível quantificar o excedente do consumidor. Contudo, conforme salientou Belluzzo Jr. (1995), somente pela utilização de suposições não muito realistas de que as curvas de demanda sejam homotéticas ou quase lineares é que se pode garantir que o excedente do consumidor quantifique com exatidão, o bem-estar do consumidor.

Em face dessas deficiências, HICKS (1940/1 - 1945/6) formulou os conceitos de variação compensatória (VC) e variação equivalente (VE).

Pode-se entender VC como o montante pelo qual se aumenta (ou diminui) a renda do consumidor, para que, após uma modificação dos preços, ele esteja tão bem quanto na situação inicial, ou seja, para que ele permaneça na mesma curva de indiferença, representada por:

$$
v\left(P_{1}, M-Z_{1} q_{1}^{0}, q_{1}^{0}\right)=v\left(P_{1}, M-Z_{1} q_{1}^{1}-V C, q_{1}^{1}\right)
$$

Em que:

M é a renda do consumidor; $\mathrm{Z}_{1} \mathrm{q}_{1}{ }^{0}$, parcela da renda gasta com o referido bem ambiental.

A primeira análise, referente à expressão (4), consiste em verificar o lado esquerdo da equação, que representa o máximo nível de utilidade obtido pelo indivíduo, dado pela quantidade $\mathrm{q}_{1}{ }^{0}$. Já o lado direito representa o máximo nível de utilidade obtido pelo consumidor, dado pelo decréscimo na quantidade do bem que disponibilizou um valorsuperior, dado por $\mathrm{q}_{1}{ }^{1}$. Consequentemente, o VC é o valor da renda que o indivíduo deve compensar pelo aumento de $\mathrm{q}_{1}{ }^{0}$ para $\mathrm{q}_{1}{ }^{1}$, de forma a permanecer no nível de utilidade inicial, ou seja, estabelecer a igualdade entre os termos da equação acima.Dessa forma, conforme salientou Freeman III (1993), a variaçãocompensatória corresponde à seguinte pergunta:

Quanto você estaria disposto a pagar para que a disponibilidade deserviços ambientais fornecidos por um determinado ativo ambientalnão diminua? Ou seja, a VC indicaquanto o indivíduo está disposto a pagarpara manter seu nível de satisfação.

A variação equivalente (VE) corresponde ao montante da variação da renda que possuio mesmo efeito sobre o nível da utilidade que uma mudança de preço. É válido ressaltarque este montante irá conduzi-lo ao nível superior de utilidade.

Como os ativos ambientais são bens públicos e não tem seus preços definidos pela interação da oferta e 
demanda no mercado, devido à dificuldade de se definir a função demanda destes ativos, a economia ambiental propõe o cálculo da disposição a pagar (DAP) em relação aos ativos ambientais, quando se utilizam métodos de valoração pelo lado da demanda.

\section{Considerações sobre o Método de Valoração Contingente (MVC)}

O MVC é baseado na revelação das preferências dos consumidores pela preservação de um determinado bem ambiental e busca estimar o valor de bens públicos para os quais não existe um valor de mercado, sendo sua utilização bastante consolidada na valoração econômica de bens ambientais e de ecossistemas.

Busca-se obter a disposição a pagar por determinado bem público (DAP - disposição a pagar) ou o quanto as pessoas estão dispostas a receber como compensação pelo não recebimento do bem em questão (DAA disposição a aceitar), que é verificada por meio da aplicação de questionários. Os questionários também buscam descrever claramente o objeto valorado, desenhar o perfil socioeconômico do usuário do ativo ambiental em questão, bem como questionar o entrevistado quanto à sua disposição a pagar pela preservação e conservação do ecossistema em estudo, ou seja, a aplicação de questionários deve identificar o verdadeiro valor que o indivíduo estaria disposto a pagar ou receber pelo bem em questão caso existisse um mercado real para o mesmo.

O MVC consiste na criação de mercados hipotéticos através das pesquisas de campo para estimar valores de DAP ou DAA. No primeiro é perguntado o quanto a pessoa está disposta a pagar pelo bem, já no segundo é perguntado o quanto a pessoa está disposta a aceitar para abrir mão do bem. Dessa forma a valoração de contingentes difere de outras metodologias na medida em que trabalha com dados obtidos através do que as pessoas dizem que fariam sob situações hipotéticas, em contraste com a observação das ações de fato tomada pelos indivíduos no mercado.

O Método de Valoração Contingente (MVC) é atualmente dos métodos de valoração um dos mais utilizados para captar o valor econômico do recurso ambiental. O primeiro estudo a utilizar o MVC foi desenvolvido por Davis (1963), o qual tinha por objetivo valorar áreas de recreação nos Estados Unidos. Pode-se destacar como um ponto forte do MVC a credibilidade atribuída ao método, cuja utilização vem crescendo cada vez maior; e como ponto fraco deve ser destacado a dependência que os resultados possuem da forma de como a pergunta do questionário está esboçada.

Vale salientar que a escolha da avaliação contingente como metodologia para valoração do rio Jaguaribe da Cidade de João Pessoa é justificada pelo fato de ser este o único método, entre tantos, capaz de realizar tal objetivo. O fato dessa reserva não agregar valor ao preço de imóveis, devido à sua localização e à existência de favelas em sua vizinhança, impossibilita a aplicação do método de preços implícitos. A aplicação do método do custo de viagem fica comprometida diante do fato de não haver relação entre este e gastos com recreação e viagens, ou seja, não atrai visitantes para justificar sua aplicação. Por fim, não há uso direto do Rio como insumo para a produção de algum bem, o que impossibilita a aplicação de qualquer instrumental de função produção.

\section{Material e MÉtodos}

A disposição máxima a pagar (DAP) foi a alternativa escolhida, em detrimento da mínima disposição a receber (DAR), por ser uma medida considerada conservadora pormuitos estudiosos da área (Motta, 1998). De 
qualquer forma, esta parece ser a alternativa mais difundida em trabalhos que envolvem a aplicação do método de valoração contingente.

O modelo econométrico escolhido para estimar a DAP é o logit, que é um modelo de seleção qualitativa, uma vez que gera respostas de procedimentos qualitativos. Por exemplo, vota-se sim ou não em uma eleição, viaja-se de carro, de ônibus ou de avião, uma empresa irá ou não a falência, etc. Assim, tal modelo possibilita a determinação da verdadeira disposição a pagar (true stated willingness-to-pay). No modelo logit, estima-se, primeiro, a probabilidade de um indivíduo se dispor a pagar e, em seguida, o preço, em que a probabilidade de obtenção de uma resposta SIM seja de 50\%, considerada o valor máximo que um indivíduo estaria disposto a pagar.

O modelo logit é baseado na função de probabilidade logística acumulada, a qual é especificada como:

$$
P_{i}=F\left(Z_{i}\right)=F\left(\alpha+\sum_{j}^{n} \beta_{j} X_{i j}\right)=\frac{1}{1+e^{-Z i}}=\frac{1}{1+e^{-\left(\alpha+\sum_{j}^{n} \beta_{j} X_{i j}\right)}}
$$

Nessa notação, Pi é a probabilidade de ocorrência de um evento, dada a ocorrência de X na observação i, para $1 \leq \mathrm{i} \leq \mathrm{k}$, onde k é o número de observações existentes. $\beta \mathrm{j}$ é o coeficiente da variável independente Xj e Zi é um índice contínuo teórico determinado pelas variáveis explicativas $\mathrm{Xj}$, sendo:

$$
Z_{i}=\alpha+\sum_{j}^{n} \beta_{j} X_{i j}
$$

Um tratamento algébrico simples sobre a equação 5 conduz a:

$$
L N\left(\frac{P i}{1-P i}\right)=Z_{i}=\alpha+\sum_{j}^{n} \beta_{j} X_{i j}
$$

A variável dependente da equação de regressão é o logaritmo relacionado à probabilidade de ocorrência de um dos dois possíveis eventos. Uma vantagem importante do modelo logit é que ele transforma o problema de predição probabilística em um intervalo [0;1] em um problema de predição de probabilidade de ocorrência de eventos no campo da reta real (Pindyck e Rubinfeld 1998).

Segundo os mesmos autores, contudo, em modelos com variáveis contínuas relacionadas a atributos, os quais servem como variáveis explicativas, pode ser necessário estimar um modelo logit no qual somente uma alternativa esteja associada a cada conjunto de valores assumido pelas variáveis independentes, ou seja, com observações individuais. Neste caso, a estimação dos parâmetros deve ser feita pelo método da máxima verossimilhança.

Este tipo de trabalho, não é incomum, Araújo (2002) realizou um trabalho com o objetivo de avaliar o Jardim Botânico da cidade de João Pessoa, feito a partir do método de avaliação contingente. A base de mensuração utilizada aqui foi a máxima disposição a pagar (DAP), captada a partir do método referendo. A estimação dos valores foi feita a partir da aplicação do modelo logit em dados primários, obtidos a partir da aplicação de questionários. Os resultados apontaram para A relação inversa entre o valor da DAP e a probabilidade de sua aceitação. Além disso, segundo os resultados verificados a DAP cresce com a idade, decrescendo a partir de um certo ponto.

Carvalho, Fonseca e Paixão (2016) também utilizando o MVC verificaram o intervalo de confiança da Disposição a Pagar (DAP) média/mediana estimada seguindo a abordagem de Hanemann (1984) determinado 
pelo método de Krinsky-Robb (1986) e estimado com a aplicação do modelo econométrico logit, sobre a Barreira do Cabo Branco/PB, o ponto mais oriental das Américas. A análise apresentou o cômputo de uma DAP individual pela visitação no valor de $\mathrm{R} \$ 15,14$. Os resultados sugeriram que, baseada no serviço cultural prestado pela falésia do Cabo Branco, e analisando os sinais estimados e o comportamento das variáveis explicativas, o sexo (masculino), a idade, o valor do lance, o local de residência (na cidade de João Pessoa) e o conhecimento da barreira são variáveis que influenciam, negativamente, a probabilidade do agente econômico pagar pelo bem em questão. Por sua vez, a renda afeta positivamente esta probabilidade.

\section{Fontes de dados}

Os dados utilizados neste trabalho foram procedentes de fonte primária, coletada mediante aplicação de questionário semiestruturado. Optou-se pelo questionário semiestruturado, neste estudo, dada a sua versatilidade. Ao mesmo tempo em que se fazem questões objetivas ao respondente, permite-se uma margem de elucubrações, dado que o respondente está formulando sua percepção acerca de um mercado hipotético que é o que se pretende capturar a partir da DAP.

O questionário fora aplicado na Universidade Federal da Paraíba (UFPB) e no Instituto Federal da Paraíba (IFPB) entre alunos e professores. A escolha por este público reflete o fato do grupo possuir mais de oito anos de estudos, ou seja, ter, em tese, menos dificuldade de trabalhar com uma análise hipotética da realidade, já que o MVC propõe a análise de um mercado hipotético.Determinou-se uma amostra aleatória de 50 indivíduos, a aplicação dos questionários deu-se nos dias de segunda-feira, terça-feira, quinta-feira no período de 22 de janeiro a 30 de janeiro de 2015.

Como variáveis qualitativas apresentam-se o nível de escolaridade e sexo. Já como variáveis quantitativas, utilizou-se o nível de renda, idade e a disposição a pagar pelo bem público (DAP).

\section{Resultados e Discussão}

Foram considerados como unidadeamostralaleatória alunos e professores da UFPB e doIFPB, de forma que o tamanho da amostra foide 50entrevistados. A maioria dos respondentes foi composta por chefes de família, correspondendo a 40\% da amostra. Em seguida vieram os membros da família comparticipação na renda familiar, com 40\%.Os naturais de João Pessoa (PB) são maioria,representando $70 \%$ do total. Quanto ao sexo, a amostra apresentou-se equilibrada, estando composta por $48 \%$ de mulheres e $52 \%$ de homens. A idade média observadafoi de 36 anos.

No que se referem às características do setor de trabalho, os que trabalham no setor público são maioria, seguido dos desempregados, como pode ser visto na Tabela 1. A renda média familiar foi de $\mathrm{R} \$ 1.916,00$. Este valor fica bem acima da renda média calculada pelo Instituto Brasileiro de Geografia e Estatística (IBGE) para o ano de 2015 no estado da Paraíba, que foi de R \$776, e isto pode ser explicado pelo número de anos de estudo dos entrevistados. 
Tabela 1 - Característica do setor de trabalho

\begin{tabular}{lr}
\hline Característica do setor de trabalho & \multicolumn{2}{c}{$\begin{array}{c}\text { Participação da } \\
\text { Amostra em percentual } \\
\text { (\%) }\end{array}$} \\
\hline Desempregado & 20 \\
Público & 36 \\
Privado & 16 \\
Autônomo & 12 \\
Informal & 16 \\
Aposentado ou pensionista & 0 \\
\hline \multicolumn{2}{c}{ Fonte: dados da pesquisa } \\
\hline
\end{tabular}

Devido ao fato da pesquisa ter sido aplicada entre professores e estudantes da UFPB e IFPB percebeuse que a maioria dos entrevistados possui nível superior incompleto, entretanto com pelo menos oito anos de escolarização (Tabela 2). A quantidade de pessoas com curso superior concluído mostrou-se significativa.

Tabela 2 - Grau de escolaridade

\begin{tabular}{lc}
\hline \multicolumn{1}{c}{$\begin{array}{c}\text { Grau de escolaridade do } \\
\text { entrevistado }\end{array}$} & $\begin{array}{c}\text { Participação da } \\
\text { Amostra }\end{array}$ \\
\hline Sem instrução formal & 0 \\
$1^{\circ}$ grau incompleto & 0 \\
$1^{\circ}$ grau completo & 0 \\
$2^{\circ}$ grau incompleto & 0 \\
$2^{\circ}$ grau completo & 0 \\
Nível superior incompleto & 76 \\
Nível superior completo & 12 \\
Pós graduação & 12 \\
\hline \multicolumn{2}{c}{ Fonte: dados da pesquisa } \\
\hline
\end{tabular}

O índice de aceitação da DAP foi relativamente alto, 47,5\% dos respondentes aceitaram o valor apresentado. Este percentual é menor para as mulheres, sendo de 45,3\% contra 49,7\% no caso dos homens. Do total de entrevistados que aceitou o valor apresentado, $15 \%$ o fizeram para valores acima de $\mathrm{R} \$ 5,00$.

A tabela 3 apresenta o interesse por questões ambientais, 76\% dos respondentes afirmaram que este interesse é alto ou médio. Carvalho, Fonseca e Paixão (2016) em seu trabalho realizado com 418 entrevistados na cidade de João Pessoa, encontraram um valor um pouco mais alto, 91,59\% dos respondentes afirmaram ter alto ou médio grau de interesse por questões ambientais.

Tabela 3 - Interesse por questões ambientais

\begin{tabular}{lc}
\hline Interesse por questões ambientais & $\begin{array}{c}\text { Participação } \\
\text { da Amostra }\end{array}$ \\
\hline Alto & 40 \\
Médio & 36 \\
Baixo & 12 \\
Não tem nenhum interesse por esse tipo de & 12 \\
questão & \\
\hline
\end{tabular}

Os principais motivos da rejeição que levaram os entrevistados a recusar o pagamento da DAP são 
apresentados na Tabela 4.

Tabela 4 - Motivos de rejeição da DAP

\begin{tabular}{lc}
\hline $\begin{array}{c}\text { Composição dos entrevistados que rejeitaram a DAP } \\
\text { apresentada segundo os motivos }\end{array}$ & $\begin{array}{c}\text { Participação } \\
\text { da Amostra }\end{array}$ \\
\hline $\begin{array}{l}\text { Motivos financeiros (está desempregado ou a renda não } \\
\text { permite) }\end{array}$ & 20 \\
Já contribui para alguma instituição de preservação ambiental & 0 \\
A obra não é do seu interesse & 12 \\
Outros & 4 \\
\hline
\end{tabular}

Observa-se que a maioria que não estava disposta a pagar a DAP é devido a motivos financeiros. Dos que responderam outros motivos, a maioria declarou que a obra é obrigaçãoexclusiva do governo cuidar de ativos ambientais. $\mathrm{Na}$ literatura esta atitude é classificada como o viés de protesto, ou seja, o agente se recusa a pagar por não considerar sua responsabilidade, o cuidado com os ativos ambientais.

O resultado aqui encontrado aproxima-se do encontrado no trabalho de Silva (2003), em que se percebe que o viés de protesto agrupa uma série de justificativas, quais sejam: a) o respondente não acredita que, ao pagar, o ativo ambiental terá melhor manutenção e será conservado; b) não acredita que necessite pagar uma taxa para que o ativo seja conservado e tenha melhor manutenção; c) já paga muitos impostos; e d) outros motivos.

A partir dos resultados referentes à DAP aberta, observa-se que o índice de rejeição é mais suave. Do total de entrevistados, cerca de 76\% dos entrevistados declararam um não valor nulo. Ou seja, mais da metade da amostra está disposta a pagar algum valor não nulo para aefetivação e manutenção do Rio Jaguaribe. $\mathrm{O}$ valor médio da DAP aberta foi de R $\$ 2,50$.

\section{Estimação do modelo}

A estimação do modelo logit, foi feita a partir do pacote gretl. Este programa parte do Método de Máxima Verossimilhança, computando a matriz de covariância, composta pelas segundas derivadas da função de verossimilhança, no cálculo da estimação. A inserção da matriz de covariância busca corrigir problemas de heterocedasticidade, inerentes ao modelo. A equação estimada corresponde a:

$$
\mathrm{Zi}=\mathrm{a}+\mathrm{b} \text { DAP }
$$

Em que $\mathbf{b}$ representa a DAP apresentada.

Tomando-se a equação (7), foi estimado o modelo, esse teve como base a amostra sem cortes. A estimativa é estatisticamente relevante considerando um nível de significância de 1\%. Os sinais observados foram os esperados. O coeficiente de determinação, $\mathrm{R}^{2}$ foi de $26,80 \%$, ou seja, $26,80 \%$ das variações na disposição a pagar são explicadas por variações na renda, sexo e idade.

No caso da DAP, quanto maior o valor desta, menor a probabilidade de aceitar o pagamento. Ainda são poucos os trabalhos utilizando esta metodologia, o trabalho de Araújo (2002) também calcula a DAP utilizando 
o método Logit e a aplicação de questionários. Semelhantemente aos resultados aqui encontrados, seus resultados apontaram para uma relação inversa entre o valor da DAP e a probabilidade de sua aceitação.

Para verificar se oefeito conjunto das variáveis é estatisticamente significante, foi utilizada a Razão de Verossimilhança (LR), veja-se Tabela 5, haja vista que a estimação foi feita a partir do Método de MáximaVerossimilhança, veja-se Gujarati (2006). Os valores desta estatística de teste indicam que o efeito conjunto dasvariáveis é relevante, considerando um nível de significância daordem de 1\%.

Tabela 5 - Estimação do Modelo

\begin{tabular}{|c|c|c|c|}
\hline Variável & Coeficiente & Erro Padrão & estatística-t \\
\hline const & 2,51505 & 74697,7 & $-0,0003$ \\
\hline DAP & $-4,94735$ & 98209,6 & 0,0005 \\
\hline \multicolumn{4}{|c|}{$\checkmark \quad$ Pseudo-R $^{2}$ de McFadden 0,348} \\
\hline \multicolumn{4}{|c|}{$\checkmark$ Logaritmo da verossimilhança 60,2563} \\
\hline \multicolumn{4}{|c|}{ Teste de razões de verossimilhanças $\mathrm{R}^{2}=26,80$} \\
\hline \multicolumn{4}{|c|}{$\checkmark \quad(\mathrm{p}$-valor 0,000000$)$} \\
\hline \multicolumn{4}{|c|}{ Critério de informação de Akaike (AIC) 0,994} \\
\hline \multicolumn{4}{|c|}{ Critério Bayesiano de Schwarz (BIC) 0,9003} \\
\hline
\end{tabular}

Fonte: Elaboração própria a partir dos resultados obtidos pelo Gretl

Segundo o MacFadden $\mathrm{R}^{2}$, que é apenas um indicador de ajuste, não tendo, portanto, o mesmo significado do $\mathrm{R}^{2}$ usual (comum ou ajustado) apresentou um valor de 0,348 . O critério de Akaike apresentou um valor de 0,994 e Schwarz 0,9003. Os critérios de Akaike e Scwartz, são utilizados para a escolha do melhor modelo a ser adotado, em termos de adequação.

\section{Considerações Finais}

O MVC permite o exercício empírico da simulação de cenários ambientais hipotéticos e através de pesquisas de campo procura captar a disposição a pagar dos indivíduos em obter uma melhoria de bem-estar ou a disposição a aceitar uma compensação por uma perda de bem-estar.

Sabe-se, entretanto, que valores podem ser subestimados ou superestimados a partir da avaliação subjetiva dos demandantes. Apesar de sua ampla utilização, o Método de Valoração Contingente é passível de críticas, sendo uma delas sua limitação em captar valores por serviços ambientais de difícil compreensão por parte dos indivíduos.

Considerando-se as limitações, o MCV é utilizado em diversos estudos que buscam captar preços de ativos ambientais, que não tem seus preços capturados no sistema de mercado. Neste estudo, através do MCV, buscou-se captar quanto valia para os agentes entrevistados a manutenção e conservação do Rio Jaguaribe, ou seja, quanto os agentes estariam dispostos a pagar para que a disponibilidade de serviços ambientais fornecidos pelo Rio Jaguaribe não diminuísse.

Os resultados da aplicação do MCV apontam que o índice de aceitação da DAP, de um valor aprioristicamente determinado, foi relativamente alto, 47,5\% dos respondentes aceitaram o valor apresentado. 
A partir dos resultados referentes à DAP aberta, observa-se que o índice de rejeição é mais suave. O valor médio da DAP aberta foi de $\mathrm{R} \$ 2,50$. A DAP aberta reflete a situação em que o respondente, a partir do cenário proposto, é deixado livre para citar quanto pagaria pela conservação do ativo ambiental. Percebeu-se que dos entrevistados, $76 \%$ mostraram-se dispostos a pagar pela conservação e manutenção do Rio Jaguaribe.

A aceitação da DAP reflete o fato de que os respondentes deste estudo aceitam pagar um valor para efetivação e manutenção de políticas de conservação do Rio Jaguaribe da cidade de João Pessoa. Neste estudo, supôs-se que a cobrança dessa taxa estaria vinculada a cobrança de um imposto, tal como, por exemplo, o Imposto Predial e Territorial Urbano (IPTU).

Em relação a estimação do modelo econométrico, observou-se que os sinais foram os esperados conforme prediz a literatura e $26,80 \%$ das variações na disposição a pagar são explicadas por variações na renda, sexo e idade.

É possível observar também que os outros 10\% dos entrevistados desta amostra, apresentaram o comportamento conhecido na teoria econômica como caroneiro (freerider), não se propondo a pagar pela conservação do bem público, esperando que outros paguem.

Assim, pode-se concluir que $76 \%$ dos respondentes estariam dispostos a pagar para que a disponibilidade de serviços ambientais fornecidos pelo Rio Jaguaribe não seja reduzida, seja conservada e mantida. O estudo atende o objetivo central quando se infere, a partir dos resultados da amostra, em termos de aceitação da DAP, que o cidadão pessoensepercebe que a existência do bem público em questão contribui para a melhoria do seu bem-estar.

Vale ressaltar que, este é um exercício empírico de pequenas proporções e que seria necessária a ampliação da amostra para maiores inferências, entretanto, os valores da DAP podem servir como uma proxy de uma tarifa ou taxa a ser cobrada pelo poder público para a criação de uma política de preservação do ativo ambiental.

\section{REFERÊNCIAS}

Araujo AFV. 2002. Valoração Ambiental: Uma Aplicação do Modelo Logit para a Avaliação Monetária do Jardim Botânico da Cidade de João Pessoa, Dissertação de mestrado, PIMES/UFPE.

Belluzzo JRW. 1995. Valoração de bens públicos: o método de valoração contingente. São Paulo: USP, 1995. 151 p. Dissertação (Mestrado em Economia) - Universidade de São Paulo.

Carvalho PSA, Fonseca MB, Paixão AN. 2016. Pagamentos por Serviços Ambientais: um exercício de valoração do Parque Cabo Branco. Anais: XIX SEMEAD - Seminários em Administração, Universidade de São Paulo. Davis RK. 1963. The Valueof Outdoor Recreation: An Economic Study of the Maine Woods. Dissertation, Harvard University.

Freeman III AM. 1993. The measurement of environmental and resource values. Washington: Resource for the Future.

Gujarati ND. 2006. Econometria básica. 4a .ed. São Paulo: Makron Books. 
Hicks JR.1945/6. The generalized theory of consumer surplus. Reviews of Economics Studies, v. 13, p. 68-73.

ICMBIO. 2014. Unidades de Conservação Federal. Disponível em http://www.icmbio.gov.br/portal/quemsomos/o-instituto.html Acesso em: 27 abr. 2014.

IBGE. 2015. Pesquisa Renda Média. Disponível em: https://www.ibge.gov.br/. Acesso em: 30 dez. 2015.

Melo AST. 2001. Projeto de pesquisa vale do Jaguaribe. Coordenação de geografia, UNIPÊ, s.p.

Motta RS. 1998. Manual para valoração econômica de recursos ambientais. Brasília: Ministério do Meio Ambiente, dos Recursos Hídricos e da Amazônia Legal, 216p.

Nogueira JM, Medeiros MAA, Arruda FST. 2000. Valoração Econômica do Meio Ambiente: Ciência ou Empiricismo? Cadernos de Ciências \& Tecnologia, vol. 17 (2), mai/ago, p. 81-115.

Pearce DW. 1993. Economic Values and the Natural World. London The MIT Press.

Pindyck RS, Rubinfeld DL. 1998. Econometric Models and Economic Forecasts, McGraw Hill/IrwinSeries, $4^{\text {th }}$ Edition.

Silva RG. 2003.Valoração do parque ambiental “Chico Mendes”, Rio Branco - Ac: Uma aplicação probabilística do método Referendum com bidding games. Viçosa: UFV. 125 p. Dissertação (Mestrado em Economia Aplicada) Universidade Federal de Viçosa). 